DOI: $10.17976 /$ jpps/2020.02.12

\title{
ФЕНОМЕН ТОТАЛИТАРИЗМА: ВЫХОД В ХХІ ВЕК
}

\section{Ю.С. Оганисьян}

ОГАНИСЬЯН Юлий Степанович, доктор исторических наук, профессор, главный научный сотрудник, Институт социологии ФНИСЦ РАН, Москва, email: dorunat@gmail.com

Оганисьян Ю.С. Феномен тоталитаризма: выход в XXI век. - Полис. Политические исследования. 2020. № 2. C. 167-177. https://doi.org/10.17976/jpps/2020.02.12

Статья поступила в редакцию: 13.02.2019. Принята к печати: 13.10.2019

Аннотация. Тоталитаризм не отошел в историю вместе с XX в. Более того, он расширил политическое пространство своего влияния до глобальных масштабов, отличаясь вместе с тем по ряду существенных признаков от феномена, омрачившего историю минувшего столетия. Обосновывая эти выводы, автор критически анализирует базовую - дескриптивную - модель тоталитаризма, которая сложилась в западной науке на основе изучения фашизма в Италии, нацизма в Германии, сталинизма в СССР. За исключением реликтовых модификаций тоталитаризм как национально-государственное явление остался в минувшем веке. Но глобализация открыла ему новые пути в XXI в., оставив в прошлом однопартийные диктатуры, массовый террор, культ вождей и прочие его свойства, описанные базовой моделью. Отошла в прошлое и замкнутая парадигма, в которой формировалась эта модель: “либеральная демократия - тоталитаризм". После развала СССР дилемма разрешилась становлением тоталитаризма либерального типа. Возглавляемые США, либерально-демократические режимы с конца XX в. навязывают западную форму демократии остальному миру с помощью необъявленных войн, цветных революций, политического давления, экономических санкций. Воспроизводство новых превращений тоталитаризма обеспечивает технологический прогресс, оснащающий его неизвестными ранее средствами тотального контроля и насилия, которые позволяют манипулировать политикой многих государств мира, их партий и правительств, регулировать деятельность интернациональных организаций. Трансформация тоталитаризма в XXI в. происходит в общем процессе обновления социально-политического устройства мира. Ведущие тенденции этого процесса, полагает автор, не отменяют возможную перспективу установления тоталитарного миропорядка, но и не делают ее фатальной.

Ключевые слова: тоталитарный режим, насилие, неолиберализм, глобализация, миропорядок.

Тоталитаризм - несомненно, социально-политический и идеологический продукт XX в., хотя иные теоретики “уводят" его генезис во времена шумерского царства и других восточных деспотий, античных империй, доколумбовых цивилизаций Америки и завоеваний чингизидов [Bernholz 2017]. Однако один из отцов тоталитаристики К. Фридрих доказывал, что “тоталитарное общество и государство не имеют исторических аналогов и являются, таким образом, абсолютно уникальными" [Friedrich 1964: 47].

Тоталитаристика сформировалась как отдельное направление обществоведения в ходе изучения западными теоретиками трех, по их убеждению, однотипных по базовым характеристикам режимов - фашистского в Италии, нацистского в Германии и сталинского в СССР. В результате возникло множество дескриптивных моделей тоталитаризма, выявляющих сущность данного феномена путем описания отличительных его признаков - едва ли не до двух 
десятков, - либо одного основополагающего - абсолютизированной роли государства, нации, вождя, партии.

К. Фридрих и Зб. Бжезинский в качестве основных черт тоталитаризма выделяют:

- государственную идеологию, охватывающую все стороны жизни общества и сфокусированную "на некоем совершенном конечном состоянии общества";

- единственную массовую партию, правящую государством и возглавляемую одним вождем;

- тотальную систему полицейского контроля над обществом, служащую интересам партии;

- всеобъемлющий контроль над средствами массовой информации и “эффективными средствами вооруженной борьбы;

- централизованное руководство национальной экономикой” [Friedrich, Brzezinski 1956: 9-10].

Эта концептуализация тоталитаризма до сих пор признается в целом западными и отечественными либеральными исследователями. Но статичность базовой модели и иных отпочковавшихся от нее разновидностей тоталитаризма ставит под сомнение их адекватность. И дело не столько в схематичности, сколько “в неспособности каждой из многочисленных моделей охватить в полной мере всю сложность феномена тоталитаризма” [Работяжев, Соловьев 2005: 324]. Это открывает простор для произвольных интерпретаций тоталитаризма применительно к политической конъюнктуре и выводит проблему из доктринального дискурса в практическую область идеологической

168 и пропагандистской борьбы. В каком состоянии сегодня этот дискурс? Или он завершился вместе с XX веком?

\section{К ИСТОРИИ ВОПРОСА}

Тоталитарный тип идеологического подчинения и политической организации масс возник в 1920-х годах как реакция на развитие демократических и социалистических движений после Первой мировой войны и Октябрьской революции в России и как “антропологический и цивилизационный слом, диагностированный Ортегой-и-Гассетом как 'восстание масс", , который “запустил процесс обратной селекции"

Фашизм, утверждал Муссолини, возник “из общей реакции века на пассивный материалистический позитивизм XIX в.” и “противостоит всем якобинским утопиям и нововведениям”, а также демократии, либерализму, пацифизму и, разумеется, социализму, который, правда, считал дуче, после войны “как учение был уже мертв". По мнению идеологов фашизма, роль государства в постдемократическом обществе абсолютна и универсальна: "Понимаемый таким образом фашизм тоталитарен, и фашистское Государство - синтез и объединение, включающее в себя все ценности, - объясняет, развивает и придает силу всей жизни народа" [Антология... 1997: 236, 237, 240]. (Советское государство и государство Муссолини некоторое время прагматично сотрудничали на межгосударственном уровне, но в социально-политическом и идеологическом ракурсе они были антиподами [Макулов 2018]).

\footnotetext{
${ }^{1}$ Сборник материалов конференции, посвященный памяти философа Григория Гутнера, был представлен в СФИ. - Вестник СФИ. 06.03.2019. URL: https://sfi.ru/sfi-today/news/bes-totalitarizma.html (accessed 01.02.2020).
} 
В отличие от итальянских фашистов, Гитлер, выражая националистический, “народный” (Völkischer) взгляд на государство, утверждал, что оно является только средством достижения цели, самая же цель состоит "в сохранении расовых основ человечества”. Крайний национализм, слитый с расизмом, - ядро воинствующей идеологии нацизма, адептам которой, считал фюрер, не следует поддаваться “боязни шовинизма, которая есть импотенция”. Несомненно, что “сердцевиной идеологии нацизма является расовая теория” [Величко 2018: 15].

Тоталитарные устремления нацистов нашли благодатную социальную почву и необходимые для их реализации неизвестные в прошлом информационные технологии, социологические, управленческие методики контроля над массами и манипулирования их настроениями и политическим поведением. Характеризуя “человеческий материал” для “массового тоталитаризма общества”, Х. Арендт отмечала, что термин “массы” применяется в отношении людей, которых в силу их политической инертности нельзя объединить ни в какую организацию, основанную на общем интересе: "Социальная атомизация и крайняя индивидуализация предшествовали образованию массовых движений, которые привлекали совершенно неорганизованных людей, типичных 'ни к чему не присоединяющихся', тех, кто по индивидуалистическим причинам всегда отказывался признавать социальные связи..." [Антология... 1997: 532].

Но почему к этой деклассированной массе примкнули и многочисленные представители среднего класса - лавочники, ремесленники, госслужащие, часть интеллигенции? Прежде всего потому, что в условиях послевоенной разрухи и экономического кризиса конца 1920-х годов в Европе социальное положение многих резко ухудшилось и стало мало отличаться от того, в котором находились деклассированные слои общества. Возникла критическая масса людей, утративших веру в возможности демократических режимов и готовых откликнуться на призывы к насильственному установлению нового социально-политического порядка.

Конечно, демократические силы могли бы использовать кризисные явления, чтобы привлечь массы на свою сторону. Исход борьбы демократов и фашистов за массы предопределила третья сила, обычно не учитываемая западной тоталитаристикой, - финансово-промышленная олигархия, которая предпочла тоталитаризм, и это - решающий аргумент против отождествления западной модели тоталитаризма с той, которая сформировалась в СССР. Поэтому исторически совершенно несостоятельна попытка уравнять сталинизм с нацизмом, как это делают авторы резолюции Европарламента, принятой в конце 2019 г. Споры не только не угасают, но и выходят на невообразимые в XX в. международные высоты, чему содействует развязанная на Западе русофобская пропагандистская кампания.

Капитал в дореволюционной России не смог сыграть роль “третьей силы” в борьбе большевиков и их противников за массы. Под руководством ленинской партии массы стали социальной основой установления нового порядка в стране без капиталистов, либеральных демократов и фашистов. Казалось бы, не сложно “вылущить" в этом порядке признаки, внешне совпадающие с теми, которые характерны для описанной модели тоталитаризма. Однако это был принципиально отличный от нее проект, призванный воплотить мечты незаурядных умов человечества о социальной справедливости под руководством партии, представляющей собой, по определению И.В. Сталина, “своего 
рода орден меченосиев внутри государства Советского, направляющий органы последнего и одухотворяющий их деятельность” [Сталин 1947: 71].

Вся жизнь советского общества замыкалась на партии и государстве, а они на личности вождя. Сращивание партийного аппарата с государственными структурами и идеологизация массового сознания - два тотальных, всеохватывающих процесса, так или иначе затрагивающих с младенчества жизнь каждого советского человека. Все созданные режимом многомиллионные общественные организации - профсоюзы, молодежные и творческие союзы, крестьянские кооперативы и т.д. - служили, по определению вождя, “приводными ремнями” для связи партии с массами в целях их мобилизации на борьбу за социализм. Формирование сталинского режима в СССР было обусловлено потребностями ускоренной модернизации страны и необходимостью ее защиты от враждебного социального окружения - обстоятельствами, ссылаясь на которые, власть оправдывала материальные лишения народа, принудительный труд, массовые репрессии, ограничения личных и гражданских свобод.

По словам И.А. Ильина, возникла всепроникающая "политическая машина", которая сковывала не только общественную жизнь, но и сознание, социальное поведение каждого человека. Этот режим, писал другой русский мыслитель Г.П. Федотов, не оставляет вне своего контроля ни одного человека, ни одного угла в его жилище, ни единого закоулка в его душе: “Религия, искусство, научная работа, семья и воспитание - все становится функцией государства" [Федотов 1931: 426].

Конечно, лишь умозрительная модель может изобразить идеально осуществленное тоталитарное общество, где все поголовно нивелированы по единому лекалу, где, по мысли Ханны Арендт, все могут стать ОДНИМ, а каждый ВСЕМ [Антология... 1997]. По словам польско-британского социолога С. Андрески, тоталитаризм может быть представлен “в чистом виде", если вычислить степень тотальности государственного контроля над жизнью подданных. По этому показателю наиболее близок к “чистому” тоталитаризму был Советский Союз в конце 1940-х - начале 1950-х годов; нацистская Германия до Второй мировой войны была тоталитарна на $85 \%$ накануне и на $95 \%$ в ее конце; фашистская Италия в целом - на 55\% [Andreski 1984: 44]. Хотя эти исчисления приблизительны и условны, они, тем не менее, отражают достоверный факт - существенные различия в уровнях тотальности, контроля над обществом, ключевым показателем которых, по предложению Андрески, можно считать степень вероятности существования независимых общественных организаций в данном государстве. Но если принять этот критерий, то как определить порог, после которого начинается подлинный тоталитаризм, а не просто возникают и в достаточной полноте реализуются отдельные его свойства? В 1930-е годы почти все государства Европы - от Португалии и Испании до Болгарии и Румынии - оказались во власти режимов фашистского типа, которые по описанной шкале мало чем отличались от режима Муссолини. С другой стороны, до его уровня отнюдь не дотягивали послесталинские режимы в СССР и в других странах “социалистического содружества". Между тем либералы до сих пор уравнивают с тоталитаризмом социализм независимо от времени и страны, в коих он формировался и затем модифицировался. Так квалифицируются, например, современные режимы в Китае и Вьетнаме с их рыночным социализмом или на Кубе, где сегодня демократии больше, чем в тех странах, которые зовутся либерально-демократическими. Правда, ис- 
следователь А. Такер ввел понятия “поздний тоталитаризм” (late totalitarianism) и “посттоталитаризм”, утверждая, правда, что менялись формы явления, но не его суть [Tucker 2015].

В политике и социальной жизни многих государств можно видеть признаки “тоталитарной модели”, определяемой “морем дефиниций”, каждая из которых обозначает отдельный тип этого феномена: “тоталитаризм без террора”, “зрелый тоталитаризм”, “просвещенный тоталитаризм”, “администрируемое общество”, “консультативный авторитаризм”, “мобилизационная система", “моноиерархическое общество” и т.д. ${ }^{2}$ Авторы книги “Фашизм, тоталитаризм и политическая религия” под редакцией британского политолога Р. Гриффина акцентируют квазиконфессиональную сущность фашизма и тоталитаризма [Fascism... 2013].

Умножение сущностей, разумеется, затемняет реальную картину исторического бытования тоталитаризма. Чтобы избежать этого, следует выйти за рамки парадигмы противопоставления либеральной демократии тоталитаризму, рассматриваемому вне учета существенных социально-политических и идеологических различий между его типами. Западная тоталитаристика развивалась в течение многих десятилетий, доктринально приспосабливая к этой парадигме трактовки событий, связанных со Второй мировой войной. Характерное для исследований такого рода уподобление нацистского тоталитаризма и тоталитаризма сталинского типа перекочевало в конце XX в. - начале XXI в. в российский дискурс [см. Тоталитаризм... 1989; Яковлев 2003: 23].

Свободны ли сами либерально-демократические режимы от элементов тоталитаризма? Не более, чем иные режимы. Сошлемся на авторитетных западных аналитиков, таких как Г. Маркузе, Э. Фромм, А. Мейер. По мнению Маркузе, сам способ организации индустриального общества, независимо от политического устройства, делает его тоталитарным: “Тоталитаризму способствует не только специфическая форма правительства или правящей партии, но также специфическая система производства и распределения, которая вполне может быть совместимой с 'плюрализмом партий', прессы, ‘соперничающих сил' и т.п.” [Маркузе 1994: 4].

Превратив рабочего в живую деталь механического конвейера и удовлетворив его потребительские запросы, Г. Форд сделал для утверждения базовых начал тоталитаризма в западном обществе больше, чем все идеологи и вожди фашизма, вместе взятые. Социальной основой либерального тоталитаризма служит масса, представленная “самовольным недорослем” с “заурядной душой” [Ортега-и-Гассет 2016: 52, 53].

Общество потребления, где человек выступает в роли материально обеспеченного, одержимого потребительством робота, огражденного от вмешательства власти в его частную жизнь, но не сознающего, что эта приватность постоянно нарушается манипуляцией его сознанием посредством телевидения и иных СМИ. А.А. Фландорфер резюмирует: “Необратимое овеществление человека, происшедшее в цифровую эпоху, а также гедонистическое сверхпотребительство поместили человека в ландшафт дистопии ${ }^{3}$, как заключенно-

\footnotetext{
${ }^{2}$ Игрицкий Ю.И. Снова о тоталитаризме. 1993. URL: http://www.fedy-diary.ru/?page_id=5802 (accessed 31.01.2020).

3 Дистопия, антиутопия (англ. dystopia) - направление в художественной литературе и кино, в узком смысле описание тоталитарного государства, в широком смысле - любого общества, в котором возобладали негативные тенденции развития. URL: https://dvc.academic.ru/dic.nsf/ruwiki/901474 (accessed 01.02.2020) (прим. Ред.).
} 
го - в его собственный паноптикум" [Flandorfer 2014: 45]. Либерализм в корне изменился с тех пор, когда он - в XIX в. - выражал стремление человека к свободе и равноправию, обратившись в идеологию финансовой олигархии. Постепенный упадок классического либерализма приводит к формированию новой Америки, в которой федеральное правительство стало "патерналистским и авторитарным образованием”, которое полагает, что знает лучше, чем кто-либо, что людям нужно для себя. Этот “новый Левиафан...”, считает политический эссеист Дж. Вэн, “...берет на себя контроль над всеми аспектами жизни людей”, а США “превращаются в то, чего отцы-основатели всячески

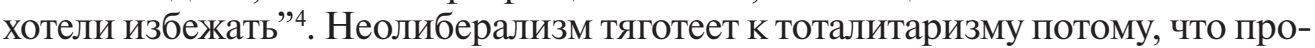
никнут имперским стремлением насильно осчастливить весь мир по меркам своих интересов и ценностей.

\section{ГЛОБАЛИЗАЦИЯ: ТОТАЛИТАРИЗМ БЕЗ БЕРЕГОВ}

Сегодня понятие “либеральный тоталитаризм" вовсе не оксюморон, а являет собой "постоянно присутствуюшую тенденцию западной цивилизации, неизбежное последствие вырождения либеральной демократии” в возрастающую милитаризацию и неолиберализм "в рамках генезиса современного капитализма". Он возникает в новой форме, в “облике либерального тоталитаризма” [Видоевич 2007: 42].

Тоталитаризм как национально-государственный феномен остался в XX в., проникнув в текущее столетие в прежних формах лишь в виде реликтовых образцов (Северная Корея), либо специфических модификаций, отражающих те или иные характерные для него признаки (диктаторские режимы в отдельных районах мира). В свое время еще Х. Арендт [Антология... 1997: 538] допускала возможность мутаций гитлеровского нацизма в современные формы шовинизма. Такие мутации можно обнаружить в странах Латинской Америки, не исключены они и в будущем. Еще до появления базовой модели тоталитаризма И.А. Ильин писал: сущность тоталитаризма заключается не столько в особой форме государственного устройства, сколько в “объеме управления”, которое становилось всеохватывающим [Ильин 2008]. Гитлеровский шовинизм и сталинский интернационализм были ориентированы на мировую гегемонию. Но, подчеркнем особо, грядущий рейх в теории, мировая система социализма на практике представляли собой социально разнородные модели миропорядка, продвигающегося к этой цели. Тоталитаризм задыхается в национальногосударственных и хронологически ограниченных пределах. Он не может бесконечно развиваться вглубь, его развитие нуждается в геополитической экспансии, в выходе за пределы обстоятельств своего времени.

Нацизм укротила внешняя сила - антигитлеровская коалиция. Отмирание сталинизма, начавшееся с кончины вождя народов, ХХ сбезда КПСС, завершилось в коние 1980-х годов фактическим вырождением партии, юридической отменой статьи советской конституции о руководящей роли КПСС. Несущая конструкция государства рухнула. Вместе с ней развалилось и самое государство. За ним последовал - заодно с официальной идеологией - и социализм как сложившаяся в России XX в. форма социального и государственно-политического устройства.

\footnotetext{
${ }^{4}$ Van G. The Totalitarian State of America: A Critique of American Government. Amazon Digital Services LLC KDP Print US 2020.
} 
Если другие страны, по социальной модели схожие с Советским Союзом, были относительно безболезненно освоены западным капитализмом, то великую державу постигла участь “политического изгоя", каковым ее стали именовать зарубежные и отечественные неолибералы спустя полтора десятка лет после развала СССР. Почему? Во-первых, неолиберальный Запад оказался не столь могуществен, чтобы экономически и политически освоить едва ли не равновеликое ему планетарное пространство. Во-вторых, постсоветская Россия вышла из социально несовместного с ним состояния, сохранив в мутированных формах - элементы политического режима и социально-экономичесого строя советского типа. Оставшиеся фрагменты былого режима органично влились в постсоветские структуры либерализма, прежде всего в виде автократических форм государственной власти.

Попытки США маргинализировать роль России в мировой политике трансформировались в войну, которую стали называть “гибридной” и которая представляет собой форму экспансии либерального тоталитаризма. Глобализация и тоталитаризация международной жизни - термины одного семантического корня, а отражающие их сущность понятия “глобальность" и “тотальность” означают всеобщность действий или состояний. Они близки и по окружающей каждую из них фетишистской ауре, придаваемой им политологами и публицистами.

Сущностные определения глобализации несут тот же смысл, что и определения тоталитаризма. У. Бек видит реальное содержание глобализации в переменах, которые вплетают “национальные государства и их суверенитет в паутину транснациональных акторов и подчиняют их властным возможностям, их ориентации и идентичности” [Бек 2001: 26].

Что оставила глобализация от прежнего тоталитаризма? Насилие? Конечно. Но масштабы его применения расширились до бесконечных, уходящих в космос, удостоверяемых не поименно некими диктаторами, а анонимной международной финансовой олигархией. На мировой арене возникает сообщество, объединенное общими политическими и экономическими интересами, которое формируется, по Зб. Бжезинскому, “отчасти как следствие спонтанной глобализации, а отчасти в результате осознанных усилий, предпринимаемых по большей части Соединенными Штатами и Европейским союзом в их попытках свить широкую сеть действенного и институционализированного международного сотрудничества" [Brzezinski 2004: 218].

Глобализация вынесла на поверхность специфическую форму тоталитарной идеологии - исламский фундаментализм, не выходивший в XX в. за национальные и региональные пределы, хотя и тогда он стимулировал появление ряда интернационально действующих (запрещенных в России) организаций и движений. Терроризм как глобальная форма насилия по уровню тотальности превзошел те формы, которыми отличился XX в., о чем свидетельствует деятельность запрещенной в РФ организации ИГИЛ, выступающей за создание Всемирного халифата путем развертывания в различных регионах мира массового террора. Страх перед террором не знает границ, и “демократические режимы абсурдно легализуют тоталитарные практики, такие как контроль со стороны спецслужб, под предлогом противостояния международному терроризму” [Chugrov 2015: 448]. Впрочем, и это становится все более очевидным, такая легализация политического насилия далеко не 
абсурдна. Общество морально согласно на тотальный контроль, так как угроза терроризма ощущается гораздо острей, чем все еще довольно абстрактная угроза ядерной войны. Как отмечает Д. Шляпентох, тоталитарные и полутоталитарные порядки порой выступают в роли чуть ли не средства обеспечить безопасность социуму, а людям предписывается “оруэлловская любовь” к правителю как к “большому брату”, которому вменяется в обязанность поддержание порядка [Shlapentokh 2017].

Погружение мира в алармистское состояние - одно из негативных последствий развития высоких технологий. Глобальная компьютеризация, интернет, цифра открывают возможности террористическим организациям координировать действия в международном масштабе. Эта практика породила кибертерроризм - деятельность, направленную на нарушение работы электронных систем безопасности и жизнеобеспечения мирного населения, хищение информации, как связанной с вооружениями, включая бактериологическое, биологическое, химическое, ядерное, так и персональной.

Тоталитаризм и посттоталитаризм XXI в. - феномены с меняющейся функциональной структурой, они с трудом поддаются идентификации, общеприемлемой для участников дискурса, так как константно адаптируются к условиям мирового развития и проделали “эволюцию от классической тоталитарной модели к элементам институционального плюрализма. Собственно, именно реальность подобной эволюции и делает феномен тоталитаризма столь трудно 'уловимым’ для исследователей, приводит к стремительному устареванию различных дескриптивных моделей тоталитарных систем” [Работяжев, Соловьев 2005: 11].

\section{ПОЛИЦЕНТРИЗМ VS ГЛОБАЛЬНЫЙ ТОТАЛИТАРИЗМ}

На фоне социально-политических трансформаций XXI в. гегемонизм внешней политики Вашингтона выглядит все более архаичным явлением. Западные аналитики в начале третьего десятилетия XXI в. порой возвращаются к использованию реликтовых понятий прежних времен, когда США пытались ослабить и вызвать распад постсоветской России. Так, в 1999 г. Бжезинский, выступая по случаю присвоения ему звания "почетный гражданин Львова", заявлял: "Украина для нас - это форпост Запада. Новый мировой порядок при гегемонии США создается против России, за счет России и на обломках России...”.

Ужесточение конфронтации с Россией производно от общего курса на распространение американского влияния на весь мир в целях установления тотального контроля над природными ресурсами, рынками, финансами, политикой других государств, усиления зависимости экономики большинства государств мира от доллара как мировой валюты, а их безопасности - от глобальной сети американских баз. В рамках этого курса реализуется система санкций, применяемых к десяткам стран, в которых проживает свыше половины населения планеты. Жертвами санкционной войны становятся даже союзники по НАТО, пытающиеся обойти антироссийские санкции. Гегемонистский курс США порожден либеральным тоталитаризмом, стремлением к "планетаризации цивилизации западного типа в его американском варианте” [Видоевич 2007: 47].

5 “Украина для нас - это форпост Запада... против России...” Збигнев Бжезинский. - MAXPARK. 23.05.2013. URL: http://maxpark.com/community//5158/content/2001896 (accessed 01.02.2020). 
Однако обновление миропорядка неизбежно, и оно не совпадает с американской картиной мира. Россия восстановила военно-стратегический паритет с США и их союзниками. Китай превратился в экономическую сверхдержаву, выступающую на равных в конкуренции с США. Заметно сократилась поддержка Вашингтона его союзниками. Многие из них озабочены - иные испуганы - иррациональностью и непредсказуемостью его внешней политики. В самом деле, какой смысл затевать новую конфронтацию, если угроза “коммунистического тоталитаризма" отошла в прошлое? Можно ли оправдать чем-нибудь иным ее поддержку, кроме защиты американских интересов? Стоит ли ради них ставить мир на грань ракетно-ядерной войны? Эти вопросы все более актуализируются. Не случайно лозунгом, с которым Трамп шел в 2016 г. на выборы, - “Сделаем Америку снова великой!" - по существу есть признание упадка былого могущества Америки. А в качестве средства сделать это вновь продвигается внешняя “экзистенциальная угроза” для США, обозначенная в Стратегии национальной безопасности как российский ядерный потенциал 6 .

Но однополярный мир, возникший после развала СССР, стал более шатким и хаотичным. В XXI в. усилились тренды, направленные к бесполюсному полицентричному миру. Этот процесс продуцирует новую, динамичную реальность - мироустройство, в котором целое представляет собой нечто иное, чем простая сумма его частей, поскольку несет с собой синергетический эффект. Ни один из сколько-нибудь реалистичных проектов нового миропорядка не предусматривает сегодня продолжение американского доминирования. Возможно, но маловероятно возрождение биполярного мира в виде конфронтации между Китаем и Россией, с одной стороны, и США и Европой - с другой, чему препятствуют явные и латентные противоречия внутри каждого из этих блоков, а также между ними и остальными государствами.

Может ли полицентризм оградить от глобального тоталитаризма мир, который уже сегодня практически полицентричен? Наряду с прежними центрами силы (НАТО, Евросоюз) в нем выделяются другие, автономные, относительно независимые, со своими сферами влияния (ЕвроЗЕС, БРИКС и др.). Каждый из них эволюционирует по собственной траектории, в рамках своей парадигмы развития, но отражает на региональном уровне общую тенденцию происходящих в мире перемен. Словом, возможность тоталитарного порядка в теории не исключена, но на практике ее реализация не представляется фатально неизбежной.

Тенденции и перспективы в этом контексте во многом зависят от воздействия на них технологического прогресса и информационных технологий. Связанные с ними социально-политические тренды зачастую неподконтрольны человеку, действуют независимо от политических и морально-этических установлений общества. Здесь два аспекта. Во-первых, такие тренды сами по себе могут грозить хаосом и, наоборот, потенциально чреваты установлением тоталитарного контроля как средства избежать хаотизации. Во-вторых, развитие сетевых технологий, кибернетики, робототехники, информатики, генной инженерии вытесняет человека из сфер производства и управления. В широкой экстраполяции этих трендов вполне допустима возможность установления такого миропорядка, который полностью отторгает человеческую деятельность, заменяемую функционированием самовоспроизводящихся человекоподобных биороботов или клонированных мутантов.

6 “Разбойники и реваншисты”: на кого Трамп нацелил доктрину нацбезопасности. - РБК. 18.12.2017. URL: https://www.rbc.ru/politics/18/12/2017/5a379c269a79472de0bf9382 (accessed 01.02.2020). 
Технологический Армагеддон? Вопрос не праздный. Научно-технический прогресс несет в себе апокалипсическое начало. Своими ядовитыми отходами он умерщвляет природу, своими достижениями в области ядерных вооружений угрожает самой жизни на Земле. Не актуален ли поэтому уже сегодня поставленный выше вопрос? Эпоха новейших технологий может стать началом становления истинно глобальной цивилизации, которая, отмечает основатель и бессменный председатель Давосского форума глобалистов Клаус Шваб, “роботизирует” человечество, и это до неузнаваемости изменит жизнь людей, саму их идентичность. Рядом с реальным миром, а не исключено - и вместо него, возникнет "виртуальная и дополненная реальность” [Шваб, Дэвис 2018]. Иначе говоря, человек может стать уходящей натурой. Способен ли он отстоять себя? Вопрос метафизический и, понятно, экзистенциональный. Ответ таится где-то в потемках будущего.

\title{
DOI: $10.17976 / \mathrm{jpps} / 2020.02 .12$
}

\section{PHENOMENON OF TOTALITARIANISM: EXIT TO THE TWENTY-FIRST CENTURY}

\author{
Yu.S. Oganisyan ${ }^{1}$ \\ ${ }^{1}$ Institute of Sociology of the Federal Center of Theoretical and Applied Sociology of the Russian Academy of \\ Sciences. Moscow, Russia
}

OGANISYAN, Yuliy Stepanovich, Dr. Sci. (Hist.), Professor, Principal Researcher, Institute of Sociology of the Federal Center of Theoretical and Applied Sociology of the Russian Academy of Sciences, email: dorunat@gmail.com

Oganisyan Yu.S. Phenomenon of Totalitarianism: Exit to the Twenty-First Century. - Polis. Political Studies. 2020. No. 2. P. 167-177. https://doi.org/10.17976/jpps/2020.02.12

Received: 13.02.2019. Accepted: 13.10.2019

\begin{abstract}
Totalitarianism did not submerge into the depths of history with the twentieth century. On the contrary, it expanded the political space of its influence globally, albeit differing in a number of essential features from the phenomenon that took shape in the past century. Substantiating these conclusions, the author critically analyzes the basic - discriminatory - model of totalitarianism that has developed in Western science, based on the study of fascism in Italy, Nazism in Germany, and Stalinism in the USSR. With the exception of relict modifications, totalitarianism as a national state phenomenon has persevered in the past century. Globalization opened its path in the twenty-first century, leaving behind one-party dictatorships, mass terror, the cult of leaders, and its other properties described by the basic model. The closed paradigm "liberal democracy - totalitarianism," in which this model was formed, has also receded into the past. Afer the collapse of the USSR, the dilemma was resolved by the establishment of totalitarianism of a liberal type. Since the end of the twentieth century, liberal democratic regimes, headed by the United States, impose a western form of democracy on the rest of the world through undeclared wars, color revolutions, political pressure, and economic sanctions. The reproduction of this newly transformed totalitarianism provides technological progress, equipping it with previously unknown means of total control and violence which allows it to manipulate the political courses of many states of the world, their parties and governments, and regulate the activities of international organizations. The transformation of totalitarianism in the twenty-first century occurs in the general process of updating the socio-political structure of the world. The leading trends of this process, the author believes, do not nullify the possible prospect of establishing a totalitarian world order, but they do not make it final either.
\end{abstract}

Keywords: totalitarian regime, violence, neoliberalism, globalization, world order.

\section{References}

Andreski S. 1984. Max Weber's Insights and Errors. L.: Routledge.

Bernholz P. 2017. Totalitarianism, Terrorism and Supreme Values: History and Theory. Cham, Switzerland: Springer International Publishing AG.

Brzezinski Zb. 2004. The Choice. Global Domination or Global Leadership? New York: Basic Books. Chugrov S. 2015. American World Order: The End of the 'End of History'. - Japanese Journal of Political Science. Vol. 16. No. 3. P. 442-449. doi:10.1017/S1468109915000110

Fascism, Totalitarianism, and Political Religion. 2013. Ed. by Roger Griffin. L.: Routledge. 
Friedrich C.J. 1964. The Unique Character of Totalitarian Society. - Totalitarianism. Proceedings of a Conference Held at the American Academy of the Arts and Sciences. March 1953. Cambridge, MA: Harvard University Press.

Friedrich C.J., Brzezinski Z.K. 1956. Totalitarian Dictatorship and Autocracy. Cambridge, MA: Harvard University Press.

Flandorfer A.A. 2014. Eschatology of Modern Totalitarianism and the Challenges of Globalization Postmodern Openings. Editura Lumen, Dep. of Economics Vol. 5. No. 3. P. 37-47.

Shlapentokh D. 2017. The Proto-totalitarian State: Punishment and Control in Absolutist Regimes. L.-New York: Routledge.

Tucker A. 2015. The Legacy of Totalitarianism: A Theoretical Framework. New York: Cambridge University Press.

Antologiya mirovoi politicheskoi mysli v 5 tomakh. 1997. [Antology of World Political Thought in 5 Volumes]. Ed. by T. Alekseeva. Vol. II. Moscow: Mysl'. (In Russ.)

Beck U. 2001. Was ist Globalisierung? (Russ. ed.: Beck U. Chto takoe globalizatsiya? Moscow: ProgressTraditsiya).

Fedotov G.P. 1931. Social Issue and Freedom. - Sovremennye zapiski. No. 47. P. 421-438. (In Russ.)

Il'in I.A. 1993. O totalitarnom rezhime [On Totalitarian Regime]. - Il'in I.A. Nashi zadachi. Stat'i 1948-1954 gg.: $v 2$ t. [Our Tasks. Articles 1948-1954: in 2 vol.]. Vol. 1. Moscow: Airis-press. (In Russ.) P. 134-136.

Makulov S.S. 2018. National press in 1922-1941 on Soviet-Italian relations. - Mezhdunarodnye otnosheniya. No. 1. P. 1-6. (In Russ.)

Marcuse G. 1994. One-dimentional Man. Studies in the Ideology of Advanced Industrial Society (Russ. ed.: Marcuse G. Odnomernyi chelovek: Issledovanie ideologii razvitogo industrial'nogo obshchestva. Moscow: REFL-book).

Ortega y Gasset J. 2016. La rebelión de las masas. (Russ.ed.: Ortega y Gasset J. Vosstanie mass. Moscow: Izdatel'stvo AST).

Rabotyazhev N.V., Solov'ev E.G. 2005. Fenomen totalitarizma: politicheskaya teoriya i istoricheskie metamorfozy

[The Phenomenon of Totalitarianism: Political Theory and Historical Metamorphoses]. Moscow: Nauka.

Schwab K., Davis N. 2018. Technologies of the Fourth Industrial Revolution (Russ. ed.: Schwab K.,

Davis N. Tekhnologii chetvertoi promyshlennoi revolyutsii. Moscow: Bombora).

Stalin I.V. 1947. O politicheskoi strategii i taktike kommunistov [On the Political Strategy and Tactics of the Communists]. - Stalin I.V. Sochineniya [Works]. Vol. 5. (1921-1923). Moscow: Gospolitizdat.

Totalitarizm kak istoricheskii fenomen [Totalitarianism as an Historical Phenomenon]. 1989. Moscow: Filosofskoe obshchestvo SSSR.

Velichko Yu.V. 2018. Sravnitel'naya politologiya. Totalitarizm v SSSR i Germanii [Compartive Political Science. Totalitarianism in the USSR]. Moscow: Yurait. (In Russ.)

Vidoevich Z. 2007. Liberal'nyi totalitarizm. - Sociological Studies. No. 12. C. 39-49. (In Russ.)

Yakovlev A.N. 2003. Sumerki [Twilight]. Moscow: Materik.

\section{Литература на русском языке}

Антология мировой политической мысли в 5 томах. 1997. Т.2 Отв. ред. Т.А. Алексеева. М.: Мысль. Бек У. 2001. Что такое глобализация? Ошибки глобализма - ответы на глобализацию. М.: ПрогрессТрадиция.

Величко Ю.В. 2018. Сравнительная политология. Тоталитаризм в СССР и Германии. М.: Юрайт.

Видоевич 3. 2007. Либеральный тоталитаризм. - Социологические исследования. № 12. С. 39-49.

Ильин И.А. 2008. О тоталитарном режиме. - Наши задачи. Статьи 1948-1954 гz.: в 2 m. T. 1. М.: Айрис-пресс. С. 134-136.

Макулов С.С. 2018. Отечественная печать 1922-1941 гг. о советско-итальянских отношениях. Международные отношения. № 1. С. 1-6.

Маркузе Г. 1994. Одномерный человек: Исследование идеологии развитого индустриального общества. M.: REFL-book.

Ортега-и-Гассет Х. 2016. Восстание масс. М.: Издательство АСТ.

Работяжев Н.В., Соловьев Э.Г. 2005. Феномен тоталитаризма: политическая теория и исторические метаморфозы. М.: Наука.

Сталин И.В. 1947. О политической стратегии и тактике коммунистов. - Сталин И.В. Сочинения. Т. 5. (1921-1923). М.: Госполитиздат. С. 62-87.

Тоталитаризм как исторический феномен. 1989. М.: Философское общество СССР.

Федотов Г.П. 1931. Социальный вопрос и свобода. - Современные записки. № 47. С. 421-438.

Шваб К., Дэвис Н. 2018. Технологии четвертой промышленной революции. М.: Бомбора.

Яковлев А.Н. 2003. Сумерки. М.: Материк. 